\title{
Computer-Assisted Instruction: Long-Term Effects on Early Literacy Skills of Low Socioeconomic Status Students
}

\author{
Haya Shamir, Erik H. Yoder, David B. Pocklington, and Kathryn C. Feehan
}

\begin{abstract}
The study investigated the longitudinal impact of computer-assisted instruction (CAI) on early literacy skills. The use of technology in the classroom has been explored in the literature, but there has been limited evidence of long-lasting effects. Pre-kindergarten students from low socioeconomic status homes in Florida were provided with a CAI program, Waterford Early Learning (WEL), while in preschool. Students did not use WEL the following year while in kindergarten. At the end of kindergarten, these students (experimental) were assessed on a literacy assessment, and their scores were compared to the scores of kindergarten students who did not use WEL (control). Differences between experimental and control groups were analyzed in terms of demographic factors, including English learner (EL) status, ethnicity, and socioeconomic status (SES). By the end of kindergarten, students who used WEL in pre-kindergarten outperformed students who did not use WEL. After using WEL, young learners from disadvantaged backgrounds benefited beyond the immediate use of the software. Large effect sizes show that students, particularly EL and Hispanic students, saw substantial, long-term, meaningful improvement as a result of using WEL. These results indicate that CAI technology can have a lasting positive effect on early literacy skills.
\end{abstract}

Index Terms-Computer-assisted instruction (CAI), literacy, early childhood.

\section{INTRODUCTION}

Efforts to improve reading instruction on a national scale, like the No Child Left Behind Act and its accompanying Early Reading First program, have moved public schools toward setting more specific goals for accountability and instructional methods for reading [1]; however, results have not proven to be unequivocally positive. The U.S. Department of Education reports that in the 2015 National Assessment of Educational Progress (NAEP), almost two-thirds of students in fourth grade and eighth grade did not perform at the Proficient achievement level in reading [2] The percentage of the student body at or above this benchmark was noticeably lower for minority students. In fourth grade, only $18 \%$ of African American students and $21 \%$ of Hispanic students achieved a reading status of Proficient, whereas $36 \%$ of the total student body scored as Proficient. This reflects the achievement gap along demographic lines, and this difference in literacy did not change significantly by eighth grade [2]. Lower academic

Manuscript received May 18, 2018; revised December 4, 2018.

The authors are with the Waterford Research Institute, Sandy, UT 84093 USA (e-mail: hayashamir@waterford.org, erikyoder@waterford.org, davidpocklington@waterford.org, kathrynfeehan@waterford.org). performance in minority students is especially concerning as most minority populations are growing [3]. Since minority students account for a rising proportion of the population of school-age children, ensuring that education is effective for all students is a necessary goal.

In addition to a racial achievement gap, students of disadvantaged families also tend to perform worse academically than their more affluent peers [4]. Within the United States, high school, middle school, elementary school, and even pre-kindergarten children from low SES households perform significantly lower on assessments of basic knowledge than their middle-class counterparts [5]. This research has revealed both the need to raise standards, and the necessity to routinely assess young children prior to kindergarten in order to determine whether they have the foundational skills requisite for academic success in formal school.

Project Head Start is a governmental program that started in 1965 with the goal of supporting young disadvantaged children with the resources they need to begin school [6]. Head Start promotes school readiness of young children from low-income families. Head Start involves "teachers facilitate[ing] individualized learning experiences to promote children's readiness for school and beyond. Through planned and spontaneous instruction, relationships with adults, and play, children grow in language and literacy, early math and science concepts, and social and emotional development" [7]. The program includes health services as well as educational resources to better prepare students for kindergarten. Studies have shown that teaching early literacy skills to young students through Head Start provides long-term benefits for those students, including a greater likelihood of graduating high school and attending college [8].

One possible way that existing intervention programs such as Head Start could be improved is through the use of computer-assisted instruction (CAI). CAI is an educational method of presenting students with different forms of interactive and instructional media. Unlike traditional large group instruction, CAI allows individual students to experience content that is consistently appropriate for their pace of learning and provides meaningful feedback [9]. A CAI curriculum can determine activities to introduce, instruct, practice, and assess based on students' performance on specific reading, math, and science skills in real time. Using an individualized curriculum increases students' flexibility, interactivity, and engagement, and it has been shown to improve young students' literacy skills [10]. CAI has been shown to benefit students at an early age: A study across 18 preschools gave students access to touchscreen desktops with 
interactive software which taught reading skills, and students who used the software scored higher in a standardized literacy test than those who did not [11].

Studies have also shown that individualized education through CAI has been effective in teaching students across different demographics. One study provided first and second grade low socioeconomic status (SES) students with supplemental CAI and compared their assessment scores to those of a control group who only received traditional reading instruction [12]. Students who used the CAI software made larger gains in literacy during the school year than their control group counterparts. Another study looked at the longitudinal impact of CAI, comparing kindergarten literacy test scores of disadvantaged students who used CAI for two school years to students who only used the software for one year [13]. Students who used CAI software during pre-kindergarten and kindergarten scored significantly higher on literacy assessments at the end of kindergarten than students who used the software during kindergarten alone. The positive effect of CAI during the two years was especially prominent for students with lower initial scores.

The students of today are experiential learners, and current schooling practices are adapting to relate to this generation's interest in games-based learning [14]. Bridging the gap from home to school, researchers have encouraged the development of technology in schools that is relative to the amount of technology that children are exposed to in the home [15], [16]. However, research has led to conflicting findings on the success of technology on digital natives in school, and there is still a gap in research on the relationship between young children's learning and developmentally appropriate technology in early reading instruction [17], [18].

The growing body of research behind CAI demonstrates that it can help foster immediate learning gains as a supplement to classroom education; however, the effects of CAI academic improvement have also been shown to be limited: One study of 1,246 fifth grade students found no statistical significance in scores between students who used a supplemental CAI program and a similar control group [19]. Additionally, a meta-analysis on the effectiveness of education technology found a range of outcomes for CAI interventions, and most positive effects of CAI were small [20]. Research has also demonstrated that the quantity of technology in education is not significantly effective unless the quality and adaptability of the technology is proficient [21]. Further research is necessary to explore the degree to which CAI can provide lasting effects on learning [22].

The current study investigates long-term effects of using CAI in an existing Head Start program: A kindergarten literacy assessment was administered to Head Start students one year after they used Waterford Early Learning and to students who did not use the software. It is predicted that students who used the software in pre-kindergarten will score higher at the end of kindergarten compared to students who did not use the software.

\section{MEthodS}

\section{A. Participants}

This study consisted of kindergarten students $(N=9,701)$ enrolled in a public school district in Florida during the 2015-2016 school year. The experimental group $(n=266)$ consisted of students who used WEL for more than 1,250 minutes during the previous school year as part of Head Start (pre-kindergarten). The control group $(n=9,435)$ consisted of students who have never used WEL.

\section{B. Materials}

\section{1) Waterford early learning (WEL)}

WEL offers a comprehensive, computer-adaptive pre-reading and reading curriculum for pre-kindergarten through second grade students. The software presents a wide range of multimedia-based activities in an adaptive sequence tailored to each student's initial placement and his or her individual rate of growth throughout the complete reading curriculum. Students gain valuable reading knowledge essential to early childhood education in just minutes during their school day - in this study, the experimental students used WEL for fifteen minutes per day, five days per week, during their pre-kindergarten school day to improve their early literacy skills.

\section{2) Kindergarten readiness test (KRT)}

The KRT is an assessment designed for kindergarten students that measures competency in reading skills. The assessment is administered to each student individually. Students are scored for each subtest, including Letter Identification (ID) and Sounds, Concepts of Print, and Phonemic Awareness, and are also given an overall score.

\section{Procedure}

Students in the experimental group were expected to use the WEL for fifteen minutes per day, five days per week during pre-kindergarten. Usage was tracked within the program and monitored weekly, and total minutes of WEL usage for the school year was calculated. The KRT was administered at the end of kindergarten, a year after students in the experimental group had stopped using WEL. Students were tested in their school district at the end of the school year and data were collected by the school district. Data were sent to the Waterford research team for analysis.

\section{RESULTS}

Independent samples $t$-tests were conducted to examine group differences on end of kindergarten year scores for each strand of KRT scores for English learner (EL) students, students of minority ethnicities, and students with free lunch status (Fig. 1-4, Table I).

\section{A. Overall KRT Scores}

\section{1) EL status}

Analysis of Overall KRT end of year scores for EL students revealed a significant difference between groups, $t(1$, $151)=-6.75, p<.01$, due to higher end of year scores made by experimental students than by control students. Effect size $(d=0.65)$.

\section{2) Ethnicity}




\section{a) African American}

Analysis of Overall KRT end of year scores for African American students revealed a significant difference between groups, $t(1,116)=-2.34, p<.05$, due to higher end of year scores made by experimental students than by control students. Effect size $(d=0.24)$.

\section{b) Hispanic}

Analysis of Overall KRT end of year scores for Hispanic students revealed a significant difference between groups, $t(1$, $165)=-3.52, p<.01$, due to higher end of year scores made by experimental students than by control students. Effect size $(d=0.30)$.

\section{3) Lunch status}

Analysis of Overall KRT end of year scores for students with free lunch status revealed a significant difference between groups, $t(1,279)=-4.42, p<.01$, due to higher end of year scores made by experimental students than by control students. Effect size $(d=0.29)$.

\section{B. KRT Letter ID and Sounds}

\section{1) EL status}

Analysis of KRT Letter ID and Sounds end of year scores for EL students revealed a significant difference between groups, $t(1,494)=-10.13, p<.01$, due to higher end of year scores made by experimental students than by control students. Effect size $(d=0.98)$.

\section{2) Ethnicity}

\section{a) African American}

Analysis of KRT Letter ID and Sounds end of year scores for African American students revealed a significant difference between groups, $t(1,142)=-2.76, p<.01$, due to higher end of year scores made by experimental students than by control students. Effect size $(d=0.28)$.

\section{b) Hispanic}

Analysis of KRT Letter ID and Sounds end of year scores for Hispanic students revealed a significant difference between groups, $t(1,298)=-7.13, p<.01$, due to higher end of year scores made by experimental students than by control students. Effect size $(d=0.61)$.

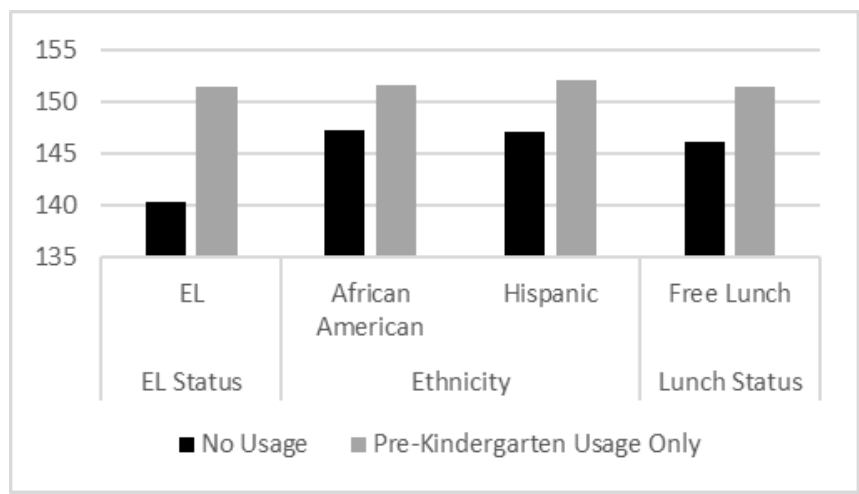

Fig. 1. KRT Overall end of year scores by demographics.

\section{3) Lunch status}

Analysis of KRT Letter ID and Sounds end of year scores for students with free lunch status revealed a significant difference between groups, $t(1,392)=-6.60, p<.01$, due to higher end of year scores made by experimental students than by control students. Effect size $(d=0.43)$.

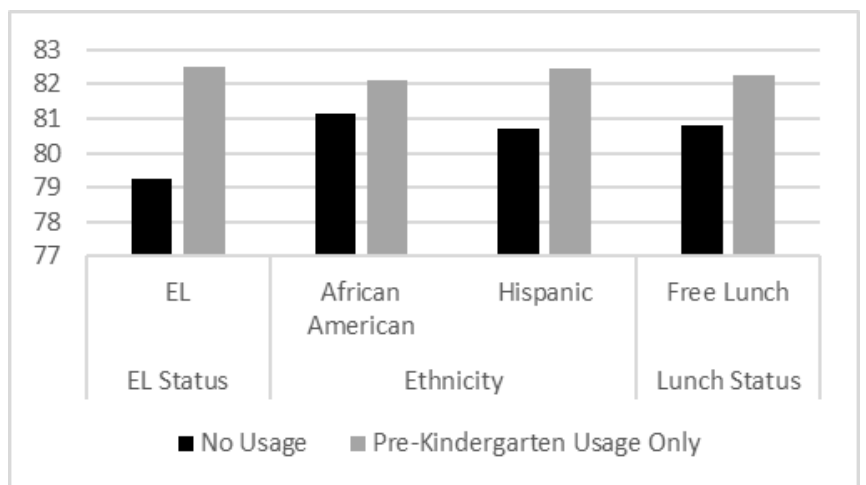

Fig. 2. KRT Letter ID and Sounds end of year scores by demographics.

\section{KRT Concepts of Print \\ 1) EL status}

Analysis of KRT Concepts of Print end of year scores for

EL students revealed a significant difference between groups, $t(1,170)=-6.55, p<.01$, due to higher end of year scores made by experimental students than by control students. Effect size $(d=0.63)$.

\section{2) Ethnicity}

\section{a) African American}

Analysis of KRT Concepts of Print end of year scores for African American students did not reveal a significant difference between groups, $t(1,2604)=-0.81, p=.421$; however, experimental students had higher end of year scores than control students.

\section{b) Hispanic}

Analysis of KRT Concepts of Print end of year scores for Hispanic students revealed a significant difference between groups, $t(1,170)=-3.45, p<.01$, due to higher end of year scores made by experimental students than by control students. Effect size $(d=0.29)$.

\section{3) Lunch status}

Analysis of KRT Concepts of Print end of year scores for students with free lunch status revealed a significant difference between groups, $t(1,266)=-2.16, p<.05$, due to higher end of year scores made by experimental students than by control students. Effect size $(d=0.14)$.

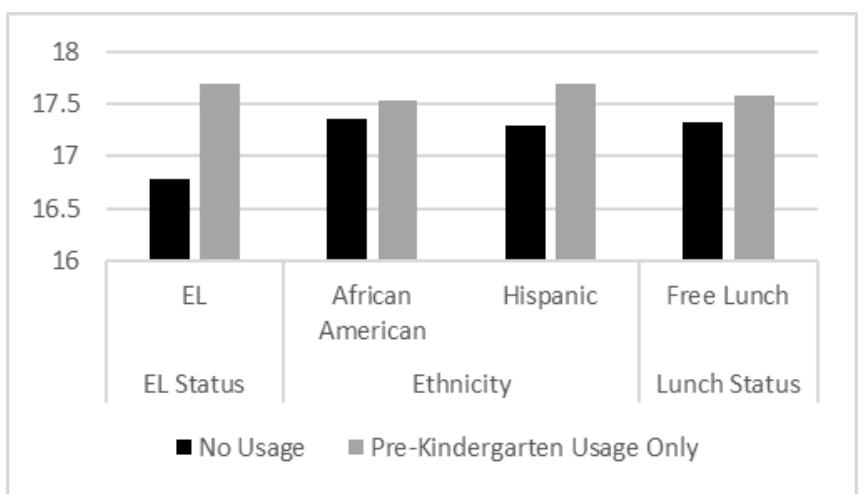

Fig. 3. KRT Concepts of Print end of year scores by demographics.

\section{KRT Phonemic Awareness}

1) EL status 
Analysis of KRT Phonemic Awareness end of year scores for EL students revealed a significant difference between groups, $t(1,143)=-5.95, p<.01$, due to higher end of year scores made by experimental students than by control students. Effect size $(d=0.58)$.

\section{2) Ethnicity}

\section{a) African American}

Analysis of KRT Phonemic Awareness end of year scores for African American students revealed a significant difference between groups, $t(1,117)=-2.15, p<.05$, due to higher end of year scores made by experimental students than by control students. Effect size $(d=0.22)$.

\section{b) Hispanic}

Analysis of KRT Phonemic Awareness end of year scores for Hispanic students revealed a significant difference between groups, $t(1,159)=-3.18, p<.01$, due to higher end of year scores made by experimental students than by control students. Effect size $(d=0.27)$.

\section{3) Lunch status}

Analysis of KRT Phonemic Awareness end of year scores for students with free lunch status revealed a significant difference between groups, $t(1,271)=-3.38, p<.01$, due to higher end of year scores made by experimental students than by control students. Effect size $(d=0.22)$.

\section{DISCUSSION}

An academic achievement gap occurs as early as kindergarten between students of different ethnicities [23] and between high- and low-SES families [4]. Providing support to disadvantaged students at an early age will help them excel academically. As a growing portion of the school-age population in the U.S. are EL and Hispanic students [3], it is more important than ever to close the achievement gap for these students. Research has shown that CAI has the potential to assist learning in young students [11], and that it can foster long term learning gains [13]. However, not all CAI interventions have been wholly positive [22].

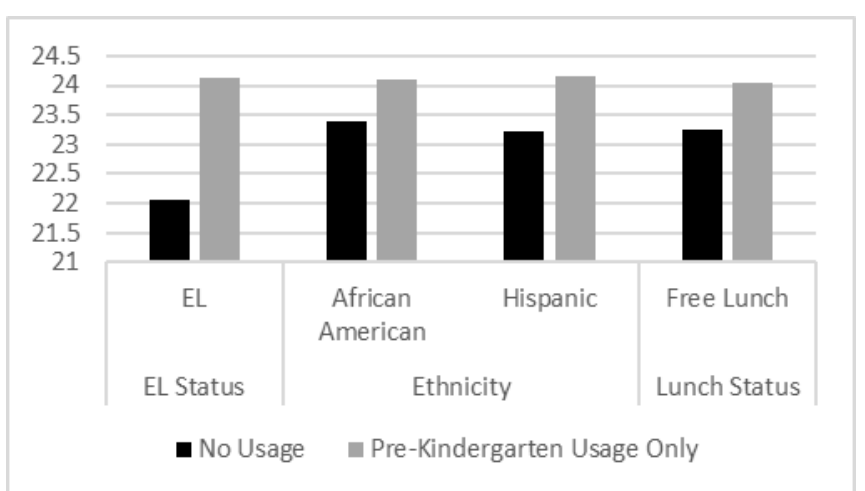

Fig. 4. KRT Phonemic Awareness end of year scores by demographics.

The current study supports the hypothesis that the use of CAI at a young age can have lasting effects on learning. Students in the experimental group exhibited significantly higher literacy assessment scores than the control group by the end of kindergarten, a full year after using the software. The experimental group outperformed the control group on the overall assessment score and on each of the substrands tested, and the differences in scores were statistically significant across almost all demographics analyzed. The large effect sizes indicate that students, particularly EL and Hispanic students, saw substantial, meaningful improvement in the long-term as a result of using WEL. The large effect sizes found for these students are especially impressive, since most research on CAI in the past decade has mixed results, and most positive effects have been small [20]. These findings are a strong contribution to the field of early childhood education, as it intersects with the use of technology in the classroom. These findings expand on the results of previous studies that demonstrate the benefits of CAI [11], and show that the impact of CAI is retained after the software is no longer being used.

TABLE I: END OF KINDERGARTEN SCORES BY STRAND AND DEMOGRAPHICS Experimental Control

\begin{tabular}{lll}
\hline$M$ & $S D$ & $N$
\end{tabular}

\begin{tabular}{llll}
\hline$M$ & $S D$ & $t$ & $p$
\end{tabular}

\begin{tabular}{|c|c|c|c|c|c|c|c|c|}
\hline \multicolumn{9}{|l|}{ Overall } \\
\hline EL Status & 151.43 & 15.98 & 111 & 140.34 & 32.27 & 2627 & -6.75 & $.000 * *$ \\
\hline African American & 151.67 & 18.16 & 100 & 147.25 & 26.37 & 2528 & -2.34 & $.021 *$ \\
\hline Hispanic & 152.06 & 16.28 & 141 & 147.04 & 27.52 & 4693 & -3.52 & $.001 * *$ \\
\hline Free Lunch & 151.44 & 17.67 & 241 & 146.21 & 27.09 & 7240 & -4.42 & $.000 * *$ \\
\hline \multicolumn{9}{|l|}{ Letter ID and Sounds } \\
\hline EL Status & 82.50 & 2.30 & 111 & 79.23 & 12.14 & 2613 & -10.13 & $.000 * *$ \\
\hline African American & 82.14 & 3.24 & 100 & 81.16 & 7.27 & 2509 & -2.76 & $.006^{* *}$ \\
\hline Hispanic & 82.45 & 2.38 & 141 & 80.72 & 9.35 & 4668 & -7.13 & $.000 * *$ \\
\hline Free Lunch & 82.25 & 2.99 & 241 & 80.81 & 8.62 & 7192 & -6.60 & $.000 * *$ \\
\hline \multicolumn{9}{|l|}{ Concepts of Print } \\
\hline EL Status & 17.69 & 1.32 & 111 & 16.78 & 3.17 & 2612 & -6.55 & $.000 * *$ \\
\hline African American & 17.53 & 2.04 & 100 & 17.35 & 2.18 & 2506 & -0.81 & .421 \\
\hline Hispanic & 17.69 & 1.31 & 141 & 17.29 & 2.41 & 4667 & -3.45 & $.001 * *$ \\
\hline Free Lunch & 17.58 & 1.79 & 241 & 17.32 & 2.25 & 7185 & -2.16 & $.032 *$ \\
\hline \multicolumn{9}{|l|}{ Phonemic Awareness } \\
\hline EL Status & 24.14 & 3.45 & 111 & 22.06 & 6.32 & 2623 & -5.95 & $.000 * *$ \\
\hline African American & 24.10 & 3.17 & 100 & 23.39 & 4.72 & 2521 & -2.15 & $.033^{*}$ \\
\hline Free Lunch & 24.04 & 3.54 & 241 & 23.25 & 4.88 & 7224 & -3.38 & $.001 * *$ \\
\hline
\end{tabular}




\section{CONCLUSION}

The results of this study demonstrate that after using WEL at a young age, minority students and those from lower SES families were positively impacted in their academic performance, improving their learning beyond the immediate use of the software.

This study found a positive impact of WEL on literacy scores; however, its ability to speak to the effect of early CAI intervention on a students' complete academic trajectory was limited since there was only one year between the students using the software and the time of the assessment. Additional follow-up with students throughout their academic career would help demonstrate the lasting effects of WEL even more meaningfully. Further research is also needed to study the positive effects of CAI on students of different backgrounds. Although the current research demonstrated the effectiveness of CAI on students of different ethnicities and from low-SES families, expanding the sample of students across multiple school districts would allow generalizability of the results.

\section{REFERENCES}

[1] D. E. Atkins, J. Bennett, J. S. Brown, A. Chopra, C. Dede, B. Fishman, and B. Williams, "Transforming American education: Learning powered by technology," Learning, vol. 114, Nov. 2010.

[2] G. Kena, W. Hussar, J. McFarland, C. de Brey, L. Musu-Gillette, X. Wang et al., "The condition of education 2016," NCES 2016-144, National Center for Education Statistics, May 2016.

[3] L. Musu-Gillette, J. Robinson, J. McFarland, A. KewalRamani, A. Zhang, and S. Wilkinson-Flicker, "Status and trends in the education of racial and ethnic groups 2016," NCES 2016-007, National Center for Education Statistics, Aug. 2016.

[4] R. Crosnoe, T. Leventhal, R. J. Wirth, K. M. Pierce, and R. C. Pianta, "Family socioeconomic status and consistent environmental stimulation in early childhood," Child Development, vol. 81, no. 3, pp. 972-987, May 2010.

[5] A. Klein and P. Starkey, "Fostering preschool children's mathematical knowledge: Findings from the Berkeley math readiness project,' Engaging Young Children in Mathematics: Standards for Early Childhood Mathematics Education, Mahwah, NJ: Lawrence Erlbaum Associates, 2004, ch. 14, pp. 343-360.

[6] M. Vinovskis, The Birth of Head Start, Chicago, IL: University of Chicago Press, 2005.

[7] Head Start, Office of Head Start, Administration for Children and Families, Head Start Programs, June 2017.

[8] R. Lee, F. Zhai, J. Brooks-Gunn, W. J. Han, and J. Waldfogel, "Head Start participation and school readiness: Evidence from the early childhood longitudinal study-birth cohort," Developmental Psychology, vol. 50, no. 1, pp. 202-215, Jan. 2014.

[9] O. O. Jethro, A. M. Grace, and A. K. Thomas, "E-learning and its effects on teaching and learning in a global age," International Journal of Academic Research in Business and Social Sciences, vol. 2, no. 1, pp. 203-210, Jan. 2012.

[10] M. E. Stetter and M. T. Hughes, "Computer-assisted instruction to enhance the reading comprehension of struggling readers: A review of the literature," Journal of Special Education Technology, vol. 25, no. 4, pp. 1-16, Dec. 2010.

[11] M. H. McManis and L. D. McManis, "Using a touch-based, computer-assisted learning system to promote literacy and math skills for low-income preschoolers," Journal of Information Technology Education: Research, vol. 15, pp. 409-429, Aug. 2016.
[12] R. Schechter, P. Macaruso, E. R. Kazakoff, and E. Brooke, "Exploration of a blended learning approach to reading instruction for low SES students in early elementary grades," Computers in the Schools, vol. 32, no. 3-4, pp. 183-200, Nov. 2015.

[13] K. P. Thai, and L. Ponciano, "Improving outcomes for at-risk prekindergarten and kindergarten students with a digital learning resource," Journal of Applied Research on Children, vol. 7, no. 2, pp. 1-29, 2016.

[14] M. Bittman, L. Rutherford, J. Brown, and L. Unsworth, "Digital natives? New and old media and children's outcomes," Australian Journal of Education, vol. 55, no. 2, pp. 161-175, Nov. 2011.

[15] B. Beschorner and A. Hutchison, "iPads as a Literacy Teaching Tool in Early Childhood," International Journal of Education in Mathematics, Science and Technology, vol. 1, no. 1, pp. 16-24, Jan. 2013.

[16] L. Plowman, O. Stevenson, C. Stephen, and J. McPake, "Preschool children's learning with technology at home," Computers \& Education, vol. 59, no. 1, pp. 30-37, Aug. 2012.

[17] C. Burnett, "Technology and literacy in early childhood educational settings: A review of research," Journal of Early Childhood Literacy, vol. 10, no. 3, pp. 247-270, Sep. 2010.

[18] C. T. Hsin, M. C. Li, and C. C. Tsai, "The influence of young children's use of technology on their learning: A review," Journal of Educational Technology \& Society, vol. 17, no. 4, pp. 85-99, Oct. 2014.

[19] A. Cheung and R. E. Slavin. (May 2011). The effectiveness of education technology for enhancing reading achievement: A meta-analysis. The Center for Research and Reform in Education, Johns Hopkins University. [Online]. Available: http://www.bestevidence.org/reading/tech/tech.html

[20] D. Bebell, L. M. O’Dwyer, M. Russell, and T. Hoffmann, “Concerns, considerations, and new ideas for data collection and research in educational technology studies," Journal of Research on Technology in Education, vol. 43, no. 1, pp. 29-52, Sep. 2010.

[21] J. Lei, "Quantity versus quality: A new approach to examine the relationship between technology use and student outcomes," British Journal of Educational Technology, vol. 41, no. 3, pp. 455-472, May 2010.

[22] M. Burchinal, K. Mccartney, L. Steinberg, R. Crosnoe, S. L. Friedman, V. Mcloyd, and R. Pianta, "Examining the black-white achievement gap among low-income children using the NICHD study of early child care and youth development," Child Development, vol. 82, no. 5, pp. 1404-1420, Sep. 2011.

[23] S. B. Neuman, E. Newman, and J. Dwyer, "Educational effects of an embedded multimedia vocabulary intervention for economically disadvantaged pre-K children: A randomized trial," Reading Research Quarterly, vol. 46, no. 3, pp. 249-272, Sep. 2011.

Haya Shamir was born in Haifa, Israel. She received her $\mathrm{PhD}$ from University of Notre Dame in 2002. She has been working at Waterford Research Institute, based in Sandy, Utah, since 2005, currently she serves as chief scientist. She has published research in multiple journals throughout her career.

Erik H. Yoder was born in Greenwich, Connecticut, USA. He earned a bachelor of arts in psychology and Norwegian from St. Olaf College, Northfield Minnesota, USA, in 2012. He is employed as a research assistant at the Waterford Research Institute, based in Sandy, Utah, US.

David B. Pocklington was born in Southfield, MI in 1987. He graduated with MS, experimental psychology, Rivier University, Nashua, NH, 2014. He currently works as a research assistant for the Waterford Research Institute, based in Sandy, UT. Her research interests include computer-assisted instruction and assessment.

Kathryn C. Feehan was born in York, Pennsylvania. She graduated with honors from the University of Pittsburgh with a bachelor of science in psychology and sociology, and she is currently working on her master of science in education at Duquesne University. She currently works at Waterford Research Institute based in Sandy, Utah. 